\title{
ESTADO, EDUCAÇÃO E A FORMAÇÃO (ANTI-CAPITALISTA) EM TEMPOS DE NEOLIBERALISMO
}

\author{
Raimundo Jucier Sousa de Assis ${ }^{1}$ \\ Francisca Jardélia Lima Damasceno ${ }^{2}$
}

\section{Resumo:}

Este artigo analisa a relação entre Estado, Formação do Professor e Educação formal como parte inerente do processo de reprodução da sociabilidade capitalista. A partir da Política Educacional mediada pelo setor público e privado, documentos são elaborados como marco regulatório do sistema de educação brasileiro a serviço dos ajustes dos arautos do neoliberalismo. Evidenciamos que a educação formal assume o papel de formar o excedente de trabalhadores para o mercado e reproduz parcela da razão instrumental como a medida do pensamento coletivo, sendo a cidadania a ideologia nacional indicada como horizonte para professores e estudantes no Brasil por meio da supervalorização das habilidades e competências no processo político-pedagógico das instituições educativas. Por fim, experiências entre Educação e Movimentos Sociais, como dos cursos superiores de Licenciatura em Educação do Campo e Escolas do Campo, tem nos possibilitado observar outros caminhos sobre a formação humana em tempos de crise da Nova República no Brasil.

Palavras-Chave: Estado, Política Educacional, Cidadania.

\section{STATE, EDUCATION AND THE (ANTI-CAPITALIST) FORMATION IN TIMES OF NEOLIBERALISM}

\begin{abstract}
:
This article analyzes the relationship between State, teacher formation and formal education as an inherent part of the process of reproduction of capitalist sociability. Based on the Educational Policy mediated by public and private sectors, documents are elaborated as a regulatory framework of the Brazilian educational system in the service of the adjustments of the heralds of neoliberalism. We evince that formal education takes on the role of forming a surplus of workers for the market and reproduces a portion of instrumental reason as the measure of collective thought, citizenship being

\footnotetext{
${ }^{1}$ Doutor pelo Programa de Pós-Graduação em Geografia Humana da Universidade de São Paulo / USP e Professor do Curso de Licenciatura em Educação do Campo em Ciências Humanas e Sociais da Universidade Federal do Piauí / UFPI. E-mail: raimundojucier@yahoo.com.br.

2 Graduada em Geografia pela Universidade Federal do Ceará e Mestre em Educação Brasileira pelo Programa de Pós-Graduação da Faculdade de Educação da Universidade Federal do Ceará/UFC.
} 
the national ideology indicated as a horizon for teachers and students in Brazil through the overvaluation of skills and competences in the political-pedagogical process of educational institutions. Ultimately, experiences between Education and Social Movements, such as the graduate courses in Field Education and Field Schools, have enabled us to observe other paths on human formation in times of crisis of the New Republic in Brazil.

Keywords: State, Educational Politics, Citizenship.

\section{Introdução}

A institucionalização do direito é a institucionalização do poder $e$, nesse sentido, um ato de manifestação imediata da violência. Walter Benjamin, em Crítica da Violência, Crítica do Poder, 2003.

O presente artigo objetiva contribuir com o pensamento da formação anticapitalista dos professores a partir da crítica a concepção de educação promovida pelo Estado, a política educacional e aos parâmetros exigidos para formação de professores nas instituições de educação formal em uma democracia neoliberal. Na busca para enfrentar as formas dominantes controladoras da Educação ajustada essencialmente ao preparo do homo economicus, o percurso do texto, de um lado, possibilita-nos alargarmos os debates sobre a educação que o Estado promove para a reprodução da sociabilidade capitalista e a forma de aprendizagem-ensino que faz da naturalização da supressão dos direitos individuais um veículo ideológico para se garantir a dita ordem a partir da cidadania e, de outro, nos serve para refletirmos sobre quais possibilidades temos para pensarmos a formação anti-capitalista do professor inserida em um projeto aberto e largo que, talvez ganhe sentido, com os movimentos anti-capitalistas em suas diversas formas de pensar e agir no mundo.

Em suma, não defendemos aqui o fim das universidades nem das escolas públicas no seu sentido de reunião com a finalidade de ensino e aprendizagem, pelo contrário, alertamos como foco central para os novos ângulos de diálogos que os professores podem oferecer a essas instituições ao relacioná-las com o processo histórico que se passa fora delas e envolve todas elas. Se a formação humana do professor exige, entre tantas capacidades, a profundidade para desnaturalizar as formas de violência e de poder que nos empurra para todos os tipos de adaptação com a

\begin{tabular}{|l|l|l|l|l|}
\hline Q Rovista Qialectus & Ano 4 & n. 10 & Janeiro - Julho 2017 & p. 127-149 \\
\hline
\end{tabular}


catástrofe dos destinos oferecidos pela vida moderna neoliberal, pensar sobre Estado, política educacional e formação do professor nesses tempos de crise do capitalismo é fazer uma crítica a educação reduzida a construção da criatividade humana restrita à produção, a circulação e a contemplação de mercadorias, e da formação de estudantes como parte do abastecimento da força de trabalho excedente de uma sociabilidade dividida entre classes sociais.

\section{Notas sobre a Concepção de Estado}

Já havia nos alertado Walter Benjamin que tratar do Estado e do Direito é construirmos uma crítica do poder-como-violência ${ }^{3}$. E, de todo modo, pensar no desfecho desse poder e da violência é o sentido da nossa reflexão nessa seção ao elaborarmos uma narrativa crítica sobre a institucionalização do poder estatal-judiciário, dos poderes individuais e, sobretudo, da classe trabalhadora. Pensar a construção de um sujeito que não esteja limitado pelas privações promovidas pela propriedade privada, pela sua situação de classe trabalhadora-violentada e, principalmente, na superação da mercadoria como a forma elementar sob a qual se estruturou o modo capitalista de produção é, assim, formular uma crítica aos fundamentos do próprio Estado moderno. É, ao final, usar do pensamento para destituir o poder que institucionaliza as forças contra a grande massa de humanos, violência esta que os impossibilita, como já foi atestado em vários derrames de sangue no passado-presente, superar o destino de ser, outra coisa, que ultrapasse a um vendedor dos seus pedaços de tempo e um usuário dos consumos das necessidades no mercado.

Numa sociedade em que sua particularidade está na enorme coleção de mercadorias para a realização das necessidades do estômago e da imaginação, como já anunciava Karl Marx nas primeiras páginas do livro $O$ Capital $^{4}$, torna-se providencial abrir esse artigo dizendo que o próprio Estado é uma forma política que deriva dessa forma-mercadoria ${ }^{5}$, isto é, que o Estado é uma forma política que também participa do

\footnotetext{
${ }^{3}$ BENJAMIN, Walter. Sobre a crítica do poder como violência. In Walter Benjamin: o anjo da história. $2^{a}$ ed. Tradução de João Barrento. Belo Horizonte: autêntica, 2013, p. 57-82.

${ }^{4}$ MARX, Karl, O Capital: crítica da economia política, Tradução Rubens Enderle, São Paulo, Boitempo, 2013.

5 "A forma-mercadoria é uma presença universal no interior do modo de produção capitalista" (HARVEY, 2013, p. 26). Isso quer dizer que se constitui como o núcleo do seu movimento - aspecto fundante da totalidade da sociedade moderna, isso por reunir um conjunto de formas sociais (formadinheiro, forma-propriedade privada, forma-força de trabalho, forma-valor, etc) que, a partir do mercado

\begin{tabular}{|c|c|c|c|c|}
\hline Rovista Aidectus & Ano 4 & n. 10 & Janeiro - Julho 2017 & p. $127-149$ \\
\hline
\end{tabular}
}


processo de acumulação do capital a partir das intervenções que faz para controlar a grande massa de humanos que está no seu território a partir da expropriação contínua, da exploração intensiva da força de trabalho e da sua normatização em defesa da propriedade privada.

É claro que para alguns que leem esse trabalho podem interpretar o que estamos refletindo sobre o Estado como um conjunto de vocábulos que não tem sentido qualquer para o nosso tempo. Há longas datas, os governantes (e mesmo grande parcela da população) tem insistido em fazer a auto-propaganda e defesa do Estado como um aparelho político institucionalizado que funciona como órgão para o "bem comum", a favor da "ordem da vida de todos", tendo a capacidade de ser a "racionalidade coletiva" de uma sociedade. Tendo sua base no Direito, o Estado é visto, por esse viés, como um aparato legal que não executa a violência e, por isso, serve a todos igualmente para o bem-estar universal da cidadania focado na realização das formas de fazer a vida de uma sociedade civil, não sendo questionado a maneira diferente e desigual que ele age com os possuidores de capital e com os trabalhadores na particularidade de uma nação moderna.

Sem dúvida G. Hegel foi um dos percussores que apontaria a resolução da dialética conflituosa da divisão social entre capital e trabalho a partir do órgão superior do Estado sobre uma sociedade civil. Como já lembrava Leandro Konder (2002), Hegel via o Estado da mesma forma como o Estado se via: defensor da propriedade privada, defensor da divisão entre ricos e pobres, órgão a favor dos proprietários dos meios de produção, razão coletiva para a resolução dos problemas individuais e lócus de pertencimento à comunidade nacional que necessita sempre de atitudes da cidadania como exercício de convivência de qualquer sociedade civil burguesa com base em leis constitucionais. Ainda dizia mais Konder, sobretudo, que teria sido Karl Marx aquele que inauguraria a recusa do aceite dessa "idéia de que a esfera estatal seria o lugar de realização da universalidade na cidadania" (KONDER, 2002, p. 29).

Poderia dizer que o estudo seminal do jovem Karl Marx, intitulado a Crítica da Filosofia do Direito de Hegel, foi um dos primeiros textos a questionar os pressupostos que punha a interpretação do Estado com essas características de portador da "razão

mundial, reproduzem continuamente o processo de acumulação ampliada do capital, a exploração da força de trabalho e o fetichismo da mercadoria como condições estabelecidas pela ordem social dominante em suas dimensões materiais e espirituais produzindo a objetividade da vida real, dialeticamente, com a construção de uma consciência subjetiva vinculado a essas formas sociais elementares do capitalismo.

\begin{tabular}{|l|l|l|l|l|}
\hline Q Rovista Dialectus & Ano 4 & n. 10 & Janeiro - Julho 2017 & p. 127-149 \\
\hline
\end{tabular}


verdadeira" de uma sociedade civil-burguesa. Nesse livro, Marx já suspeitava que o Estado não se tratava de um "agente neutro" e que as leis (o direito estatal de maneira ampla) não representava uma igualdade social, nem a fraternidade política e muito menos a liberdade cultural no mundo dos humanos. Assim, como a religião, o direito preenchia a ideia de ordem superior e também dotava (os representantes estatais) de uma perspectiva prática isolada-concentrada que afastava as decisões do mundo dos homens para um mundo jurídico meta-humano (nos termos melhores, como uma "história metafísica") ${ }^{6}$.

A pista deixada pelo jovem Marx, se assim queiramos prosseguir sobre o debate do Estado, encontra continuidade teórica e amplitude filosófica no livro de Alysson Leandro Mascaro (2013b), intitulado Estado e forma política ${ }^{7}$. Essa obra levanta a teoria que o Estado é o terceiro membro da relação entre capital-trabalho, ou seja, o Estado que no plano da aparência se manifesta como um aparato de poder institucional separado dos interesses particulares dos indivíduos, dos grupos e das classes tem, substancialmente, a função de realizar, no seu íntimo, a forma política de dominação e de violência necessária para a reprodução das relações sociais capitalistas. Eis o motivo de Mascaro interpretar a origem do Estado derivada da forma-mercadoria como núcleo central da sociabilidade capitalista, tendo sua inspiração, como ponto de partida, uma interpretação própria do Estado a partir que compreende a forma-mercadoria n'O Capital de $\operatorname{Marx}^{8}$.

Dizer que o Estado é uma forma política que deriva da forma-mercadoria, primeiro, é deixar claro que essa forma política é particular do conjunto de relações sociais constituídas no processo de ocidentalização, a partir do fluir histórico de formação da propriedade privada, do trabalho assalariado, da acumulação de capital e do processo contínuo de espoliação e montagens dos Estados para administrar politicamente essa mundialização em formação, mesmo que a semântica Estado e sua

\footnotetext{
${ }^{6}$ Podemos elencar aqui A Luta de Classes na França $(1848$ - 1851) e O 18 de Brumário de Luis Bonaparte. Um breve resumo dessa perspectiva e das outras obras de Marx e Engels que nos ajuda a pensar uma teoria do Estado, pode ser consultado em MASCARO, Alysson L. A Crítica do Estado e do Direito: a forma política e a forma jurídica. Anais do IV Curso Livre Marx e Engels: A Criação Destruidora. São Paulo: Boitempo, 2013a (p.14-18).

${ }^{7}$ MASCARO, Alysson L. Estado e Forma Política. São Paulo: Boitempo, 2013b (132p)

8 “Tal reflexão será sistematizada por Marx n'O Capital, na medida em que desvenda, na própria lógica do capital, os elementos necessários e fundadores de sua sociabilidade e sua reprodução. A mercadoria é seu núcleo - lastreado, em especial, na universalidade do trabalho assalariado como mercadoria - que estabelece uma totalidade social calcada nas formas de valor, da subjetividade jurídica, do apartamento da política em face dos agentes de produção. O Estado e o direito aí encontram sua natureza estrutural. Não se trata apenas de procurar quem os controla, tampouco a luta por eventuais ganhos parciais em suas bases. Estado e direito são, irremediavelmente, manifestação do capital” (MASCARO, 2013a, p. 17)
}

\begin{tabular}{|c|c|c|c|c|}
\hline Rovista Dialectus & Ano 4 & n. 10 & Janeiro - Julho 2017 & p. $127-149$ \\
\hline
\end{tabular}


figura como ente político já existisse nos tempos de outrora ${ }^{9}$; segundo, o Estado como nós o concebemos aqui foi formado para administrar os mercados nacionais e constituir o mercado mundial, trata-se de um centro do poder político que, de fato, é apartado da econômica, entretanto, sua forma política foi erigida para reproduzir a sociabilidade capitalista $^{10}$. Isso não quer dizer que estamos reduzindo o Estado ao econômico, pelo contrário, trata-se apenas de revelar que sua separação "aparente" da economia (dos proprietários diretos) foi a maneira encontrada pelas classes dominantes para administrar o processo de reprodução das relações de classe; terceiro, dizer que o Estado é derivado da forma-mercadoria também é revelar à sua maneira de tratar o indivíduo. Nas sociedades estatais modernas, o indivíduo torna-se "sujeito de direito" (claro, num Estado de Direito), marcado por uma forma jurídica (sendo a maior delas a constituição nacional), estando, assim, cada um livre no sentido liberal. Essa liberdade diz respeito a possibilidade de circular, de vender e comprar mercadorias (força de trabalho e todos os outros artigos de comércio no mercado), de aceitar a lógica do dinheiro como a mediação para satisfazer as necessidades e, ainda, se refere a necessidade de assumir "direitos e deveres" no âmbito das possibilidades individuais que tem como tribunal a forma jurídica: o poder judiciário.

É nesse sentido que podemos dizer que a forma política estatal é fruto do nosso tempo moderno, ou melhor, é uma das dimensões de sustentação das contradições da modernidade, sendo sua função organizar, julgar, inserir e criar as possibilidades de reprodução da sociabilidade capitalista. Além do que, ao fazer isso, o Estado moderno assume a função de proteger a propriedade privada, as relações capitalistas de produção e as classes dominantes que passam a se apoderar da dimensão jurídica para a exploração da força de trabalho e o acúmulo de capital, transformando processos violentos em extremos dados naturalizantes sobre o movimento da sociedade, enquadrados no interior dos chamados marcos legais.

\footnotetext{
${ }^{9}$ A forma Estatal tem sua origem na crise do feudalismo a partir da instalação de Estados Absolutistas, porém, defende Alysson Mascaro (2013b) que os Estados que conhecemos hoje tem seus conteúdos promovidos pelas revoluções burguesas (revolução francesa, principalmente) nas quais gestaram um Estado que tem a função de administrar o capitalismo no processo de constituição de uma sociedade comandada pela classe mercantil. Para saber sobre a origem dos Estados e do desenvolvimento geográfico desigual dos Absolutistas, pode ser consultado o livro de ANDERSON, Perry. Linhagens do Estado Absolutista. São Paulo: Brasiliense, 2004.

${ }^{10}$ Sobre a consolidação desigual dos Estados, a construção da história da sociedade mercantil e sua ligação com a operacionalização geográfica do capitalismo liberal, ver: HOBSBAWM, Eric. A Era do Capital. Rio de Janeiro. Editora Paz e Terra, 2007.
}

\begin{tabular}{|l|l|l|l|l|}
\hline Ronista Dialectus & Ano 4 & n. 10 & Janeiro - Julho 2017 & p. 127-149 \\
\hline
\end{tabular}


Para Alysson Mascaro (2013), isso não quer nos dizer, primeiro, que a forma política estatal se trate de uma estrutura inerte e atemporal, pelo contrário, sua forma só pode ser compreendida de modo relacional, sendo necessário ligar sua "internalidade" (as características e as configurações próprias de um poder político impessoal e apartado da economia da sociedade) com a sua "externalidade", isto é, sua posição no conjunto das relações capitalistas de cada período; segundo, dialético a essa primeira questão, como uma forma terceira da dinâmica do capital, a forma política estatal se materializa em instituições de forma contraditórias e com importâncias várias. Dizer que as relações da forma política (Estado) e suas instituições nos possibilitam entender como as contradições da história se materializam, não se trata de criar um nexo causal, mas de buscar entender como no conjunto das relações sociais dotadas de conflitos configuram e reconfiguram (até fragmentam) as instituições e seus conteúdos em diferentes conjunturas mesmo que a forma política continue tendo sua continuidade.

Nessa perspectiva, as instituições também assumem disputas particulares e importâncias singulares no processo de reprodução da sociabilidade capitalista. Para que não demoremos muito, podemos afunilar e dizer que na dimensão peculiar das instituições envolvidas com a Educação oficial não há dúvidas da importância delas para o processo de "valorização do valor" ou "na reprodução da sociabilidade capitalista" que, entre alguns elementos, se destacam: a formação da futura mercadoria força de trabalho; a disciplina do corpo e da mente para o processo de naturalização da vida coletiva, principalmente, das desigualdades sociais; o ensino dos comportamentos que sejam concebidos como adequados para a realização da cidadania, como o sufrágio eleitoral, o nacionalismo, o regionalismo e o localismo, o respeito moral a individualidade das escolhas do "outro" (ainda não podemos esquecer do tempo de encarceramento das crianças e adolescentes por um tempo determinado do dia - quando tratamos das escolas) e, no geral, as instituições da educação assumem o papel de promover o sentido histórico linear jurídico, marcado pela ideologia dominante centrada no trabalho e no consumo como conquista de realização da cidadania e da "liberdade" anunciada.

As democracias modernas são gêneros administrativos que se dão sob a mesma forma política (o Estado) dos regimes totalitários das ditaduras que assassinam, prendem, encarceram pedaços da vida e ameaçam de exclusão/extermínio todos aqueles que colocam em xeque a forma jurídica e a forma política estatal que servem de suporte a sociabilidade capitalista produtora de mercadorias. Como um Estado que realiza a

\begin{tabular}{|l|l|l|l|l|}
\hline Rovista Dialectus & Ano 4 & n. 10 & Janeiro - Julho 2017 & p. 127-149 \\
\hline
\end{tabular}


violência para se atingir a paz e a supressão dos direitos individuais para garantir a cidadania se envolveria com a educação de pessoas desnudas de propriedades e com a formação de professores para contribuir na formação das consciências com essas pessoas? Como as políticas educacionais refletem a imagem e semelhança do nosso período educacional e neoliberal? Seria a educação a oportunidade da disciplina espiritual e física para que os futuros trabalhadores aprendam a fabular sobre o mundo da exploração do trabalho em vez da possibilidade de liberdade promovida por uma revolução social que promova a abolição da forma-mercadoria e, em conjunto, do poder-como-violência da forma política?

\section{Política educacional, Educação e cidadania para a sociabilidade capitalista}

As relações entre a forma política estatal e as instituições de educação pública oficial na periferia do capitalismo se conformam, no interior dos Estados - desde o início do século XIX e, principalmente, durante todo o século XX e nesses primeiros anos de século XXI -, como um encontro inexorável de seguimento do processo material de constituição da formação em geral da classe trabalhadora e, dialeticamente, na formação de uma "razão instrumental". Essa forma de racionalidade, a rigor das tendências contemporâneas dominantes do projeto neoliberal para a formação de professores, revela a junção ideológica da ciência, da tecnologia e do Direito na conformação do regime de acumulação flexível $^{11}$ nos setores da sociedade. Portanto, a relação entre Estado e Educação oculta o vínculo direto com a sociedade de mercado, sendo a Política educacional e a concepção de educação (neo)liberal as medidas para reproduzir a ideologia da classe dominante e a formação de força de trabalho como princípios centrais da educação formal.

A conjuntura da política educacional para as instituições de educação formal e para a formação de professores no Brasil é demarcada por uma racionalidade educativa

\footnotetext{
11 Na obra Condição Pós-Moderna, David Harvey afirma que a acumulação flexível demarca a reestruturação dos processos produtivos e reajustamento político e social da sociedade a partir da crise das décadas de 1970 e 1980 configurada pelo confronto com a rigidez do fordismo. Para esse autor, esse regime de acumulação "se apoia na flexibilidade dos processos de trabalho, dos mercados de trabalho, dos produtos e padrões de consumo. Caracteriza-se pelo surgimento de setores de produção inteiramente novos, novas maneiras de fornecimento de serviços financeiros, novos mercados, e, sobretudo, taxas altamente intensificadas de inovação comercial, tecnológica e organizacional. A acumulação flexível envolve rápidas mudanças dos padrões do desenvolvimento desigual(...).”(HARVEY,2010,p.140).
}

\begin{tabular}{|l|l|l|l|l|}
\hline Q Rovista Dialectus & Ano 4 & n. 10 & Janeiro - Julho 2017 & p. 127-149 \\
\hline
\end{tabular}




\section{Raimundo Jucier Sousa de Assis / Francisca Jardélia Lima Damasceno}

baseado nos interesses econômicos, sociais e políticos cujos padrões ideológicos da educação são orientados pela hegemonia das agências multilaterais, organizações internacionais e grupos empresariais. Assinala Gentili (1998), que o programa de reformas educacionais amparada pelo neoliberalismo, por exemplo, expandiu-se progressivamente em boa medida nos países da América Latina. As "recomendações" tecnocráticas provenientes dos documentos do Banco Mundial e do Fundo Monetário Internacional - FMI têm penetrado os Ministérios da Educação desses países, influenciando as políticas públicas designadas a esfera educacional.

A manifestação das intendências desse projeto neoliberal na formação dos professores na contemporaneidade reelabora a defesa da razão técnica instrumental sob o aparelhamento das políticas educacionais de acúmulo de forças no cotidiano das universidades pautadas na ambivalência das habilidades e competências, potencializando a alienação tecnicista do conhecimento da prática docente nos cursos de licenciaturas. Gentili (1998, p.19), mais uma vez, desencadeia uma análise apurada acerca da competitividade como instrumento regulador do mercado, onde ocorre à transferência da educação da esfera política para a esfera do mercado, prejudicando as condições de direitos sociais atribui, por outro lado, valorização ao consumo individual, da meritocracia e competição privada.

Apenas uma concepção de educação que negue a força do mercado na regência da vida, da ideologia dominante como forma universal de pensar e da divisão de classes sociais como a naturalidade da vida humana serve para o Estado e as instituições formais reprodutoras da sociabilidade capitalista. Por isso, cabe com esmero recordar, que desde Escola e Democracia, o professor Dermeval Saviani (1984) apontava que no interior das instituições oficiais dos Estados nacionais se conformou uma concepção de “educação" separada (ou deslocada) da própria interpretação do que seria a "sociedade". Tal conceito tem seu cerne no entendimento que a "educação" possui uma "autonomia" perante a sociedade, esta sendo considerada "essencialmente harmoniosa", sendo seus problemas (no caso de Saviani a explicação da marginalidade, ou seja, da reprodução na sociedade de uma classe expropriada-explorada) vistos pelo ângulo do empirismopositivismo-naturalismo, como problemas das civilizações que precisariam de correções. Portanto, conclui o autor, que a importância da educação para os próprios Estados, assim, estaria em corrigir essas distorções aparentes, sendo a integração de todos ao "corpo social geral" a favor do projeto da integridade da comunidade nacional, o sucesso de tal concepção.

\begin{tabular}{|l|l|l|l|l|}
\hline Q Rovista Dialectus & Ano 4 & n. 10 & Janeiro - Julho 2017 & p. 127-149 \\
\hline
\end{tabular}


Algumas teorias, como da pedagogia tradicional, da pedagogia nova e da pedagogia tecnicista, são exemplos, por parte do autor, dos diversos desdobramentos teórico-práticos que este conceito de educação institucional encerrou na produção de distintos campos teóricos e práticos quando se tem em mira a compreensão da educação ideologicamente separada da prática social, ou melhor, que não reflete a própria realidade de como é planejada e executada o projeto de educação nacional e nem a vida daqueles que estão envolvidos numa realidade ${ }^{12}$. Dessa forma, essa concepção ainda fomenta uma espécie de fechamento institucional, descontextualizando os sujeitos das experiências espaço-temporais vividas, buscando resolver seus problemas a partir delas mesmas, ou seja, no interior das próprias instituições que tratam da educação (epistemologia da prática interna a escola), olhando para a realidade como algo finalizado que precisa ser reproduzida e de reformas pontuais na educação que passam pelo plano da aceitação e dos comportamentos dos "sujeitos de direito" para o mundo da disciplina da venda da força de trabalho.

Essa concepção de educação formal separada forçadamente da prática social da realidade, com astúcia, afirma que os problemas que são produtos das contradições da sociedade capitalista (como a relação entre capital-trabalho) precisam apenas de "uma regulação mais exata" em suas margens, regulação essa que se deve e que pode ser alcançada pelas políticas públicas, isto é, por medidas que István Mészáros (2008) tem criticado como a "metodologia do pouco a pouco", afirmando, essa atitude, fazer das instituições da educação, principalmente, a escola, um lugar para o Estado visto apenas para realizar "tarefas" disciplinares e de "construção de uma razão instrumental", levando, assim, a formar um professor que recuse os saberes e as teorias que efetivamente não conseguem ser "praticadas", "utilizadas" e "planejadas" no interior dos espaços escolares como "conto de fadas", ou mesmo, "idealismo" que não servem para o processo educacional.

\footnotetext{
${ }^{12}$ Segundo Dermeval Saviani (1984), essas teorias vão ter, como diferenças internas, os debates e as práticas no que se referem à centralidade ou a não centralidade que o professor deve assumir no processo educativo, sendo a educação tradicional marcada pela centralidade total, a educação escolanovista pela descentralização total e a educação tecnicista pela instrução ou monitoramente. No entanto, as três teorias tem como similar a reprodução das próprias desigualdades sociais mesmo que a pedagogia da educação tradicional tenha como proposta ensinar os conhecimentos acumulados pela humanidade de maneira sistematizada, a pedagogia da educação escolanovista dizer que é possível aprender a aprender os saberes espontâneos e não direcionados e a pedagogia tecnicista cultue a necessidade utilitarista de aprender a fazer e adaptar o estudante mais cedo ao processo de trabalho, como hoje conhecemos as escolas técnica e o ensino profissionalizante, todos elas naturalizam totalmente a realidade da sociabilidade capitalista dividida entre classes sociais.
}

\begin{tabular}{|l|l|l|l|l|}
\hline Ronita Cialectus & Ano 4 & n. 10 & Janeiro - Julho 2017 & p. 127-149 \\
\hline
\end{tabular}


Com base teórica que sustenta nossa argumentação crítica, destacamos que os cursos de licenciaturas são notadamente atravessados por mediações externas e internas aos espaços acadêmicos. Preocupa-nos o modo como a racionalidade técnica instrumental corrompe a dimensão da totalidade do conhecimento na formação humana, fragmentando a dimensão política do conhecimento na formação do professor - também trabalhador. Com isso, deflagra-se a iminente fragilidade da relação teoria e prática, do ensino e pesquisa, Universidade e Escola, e, na complexidade desse processo o lema "aprender a aprender" tornou-se fórmula da pedagogia das competências para a legitimação do reducionismo da formação docente posta à tendência do "praticismo" no/do ensino.

Em suma, a "pedagogia das competências" apresentam-se como outra face da "pedagogia do aprender a aprender", cujo objetivo é dotar os indivíduos de comportamentos flexíveis que lhe permitam ajustar-se às condições de uma sociedade em que as próprias necessidades de sobrevivência não estão garantidas. Sua satisfação deixou de ser um compromisso coletivo, ficando sob a responsabilidade dos próprios sujeitos que, segundo a raiz etimológica dessa palavra, se encontram subjugados à "mão livre do mercado". (SAVIANI, 2008, p.437).

É preciso ainda ratificar que o fechamento dessa concepção que tem como saída teórica o conceito de educação separado da prática social (ou concebendo a sociedade de maneira harmoniosa) constrói, ao negar a leitura da sociedade dividida entre classes, uma leitura que: primeiro, estimula o desengajamento radical necessário por parte do educador e de todos na luta por uma sociedade sem classes sociais; segundo, reforça em todos que educam uma perspectiva liberal individualista que analisa o indivíduo como a menor partícula da comunidade nacional. Centrada no avesso, o esforço dessa educação, assim, atinge seu zênite na formação do dito "cidadão" para uma dita "democracia nacional" 13 .

Torna bastante irônico pensar sobre isso, pois a culminância do debate sobre a cidadania se deu a partir da Nova República marcada pelas lutas dos setores sociais de

\footnotetext{
13 “A ideologia da nação constrói um espaço simbólico de amálgama por sobre as classes. Assim, antes de ser burguês ou proletário, o indivíduo vislumbra pertencer a uma nação. A forma política estatal busca duplicar como nação como meio de constituir uma unidade social para além das classes. (...) Assim, a ideologia da nação é um elemento que reforça, em cheio, a submissão dos explorados no capitalismo" (MASCARO, 2013, p. 79).
}

\begin{tabular}{|l|l|l|l|l|}
\hline Q Povista Dialectus & Ano 4 & n. 10 & Janeiro - Julho 2017 & p. 127-149 \\
\hline
\end{tabular}


base organizada no campo e na cidade, propondo a busca de terreno sólido de crítica e ação destinado ao enfrentamento da Ditadura Militar e reabertura democrática do Brasil. No entanto, atentamente Peroni (2003, p74) avalia e nos entrega pistas ao interpretar que a Nova República se deu "pelo alto", "havendo, assim, apenas uma reorganização do poder necessária para que as mesmas classes dominantes continuassem dirigindo o país”. Porém, esta mesma autora explica que foi no contexto da Nova República que “outras forças da sociedade aliaram-se na luta pela democracia. Muitas entidades nasceram nesse período, como é o caso do Partido dos Trabalhadores (PT) e da Central Única dos Trabalhadores (CUT).” (idem, p.74). Nessa mesma linha de reflexão sóciohistórica, Krawczyk; Vieira (2008) imputa que as demandas sociais da educação foram mobilizadas de acordo com a necessidade de ajustar as diretrizes internacionais e as novas formas de gestão da educação e escola.

Dessa forma, Peroni (2003) ainda aprofunda a investigação dos projetos do Executivo e do Legislativo apresentado nos anos de 1980 e 1990 direcionado a educação, e nesse ínterim põe em análise os espaços de articulação de natureza acadêmica, política e sindical nos fóruns, eventos onde se colocava o papel das entidades na organização do movimento de "balanço" da situação da educação e sua emergente necessidade de mudança. Porém, a nós interessa tocar que uma das nuances da Política Educacional a partir de meados de 1990 expressada na Lei de Diretrizes e Bases da Educação Brasileira Parâmetros Curriculares Nacionais do Ensino Médio (PCN), Exame Nacional do Ensino Médio (ENEM) Referenciais Curriculares Nacionais para a Educação Profissional (RNC), Diretrizes Curriculares para a Formação de Professores (DCN), Programa de bolsa à Iniciação a Docência (PIBID) e mais recentemente o documento em processo de desenvolvimento a Base Nacional Comum Curricular (BNCC). Esses documentos são legitimados como suporte a falsificação da formação para a cidadania em formação profissional através de pacotes educacionais a serviço da lógica da necessidade e eficiência dos arautos do neoliberalismo, cuja formação dos professores configura-se a adaptabilidade flexível às situações problemas da sala de aula, amparado, nesse sentido, por uma concepção neoconstrutivista e neotecnicista da relação ensino e aprendizagem no cotidiano dos espaços educativos formal, a tocar diretamente a cidadania como um direito a educação e o senso crítico como um resultado do processo de ensino aprendizagem, no entanto, não debate a fundo nem uma coisa nem outra.

\begin{tabular}{|l|l|l|l|l|}
\hline Q Ronista Dialectus & Ano 4 & n. 10 & Janeiro - Julho 2017 & p. 127-149 \\
\hline
\end{tabular}


Sob a cidadania oculta-se um princípio educativo e um princípio de sociabilidade que a concepção de educação separada da sociedade agregada como parte de uma ideologia nacional. É esse o vínculo, Educação e Cidadania, um dos mais promissores dessa concepção de educação vinculada ao mercado: formar um professor e um estudante para o capitalismo, ao mesmo tempo, que se sente cognitivamente parte dele, pois o conceito de "cidadania" aos moldes oficiais "elimina" a luta de classes e os indivíduos aparecem com seus conteúdos voltados para a prática individualista na sociabilidade capitalista. E constrói ainda, essa ideologia da nação um discurso para todos os indivíduos isolados, via uma poeira jurídica da forma política estatal de direito e deveres, isso ao entender que cada pessoa é um membro individual, atomizado e imediato. Abrangendo essa compreensão, a pedagogia das competências enquanto eixo do projeto de educação neoliberal de formação do trabalhador posto entre o direito subjetivo e o negócio (FRIGOTTO, 2010). Uma vez que para essa tendência aos educadores

[...] caberia conhecer a realidade social não para fazer a crítica a essa realidade e construir uma educação comprometida com as lutas por uma transformação social radical, mas sim para saber melhor quais competências a realidade social está exigindo dos indivíduos. Quando educadores e psicólogos apresentam o "aprender a aprender" como síntese de uma educação destinada a formar indivíduos criativos, é importante atentar para um detalhe fundamental: essa criatividade não deve ser confundida com busca de transformações radicais na realidade social, busca de superação radical da sociedade capitalista, mas sim criatividade em termos de capacidade de encontrar novas formas de ação que permitam melhor adaptação aos ditames da sociedade capitalista. (DUARTE, 2008, p.11).

Essa concepção de cidadania individual-formal é, na dimensão profunda, o próprio processo de subjetivação institucionalizado da sociedade capitalista, das distorções jurídica das relações sociais como contraditórias e da transformação dos problemas de classes em problemas individuais ou de grupos ("problema da população", "problemas do bairro", "problemas do Brasil”, por exemplo), sendo as responsabilidades de superação dotada de iniciativa individual, de competências pragmáticas, de políticas públicas e, assim, da competição "solidária" típica dos países do capitalismo. O conceito de "cidadania" serve, ao final, como parte do encadeamento

\begin{tabular}{|l|l|l|l|l|}
\hline Q Ronista Dialectus & Ano 4 & n. 10 & Janeiro - Julho 2017 & p. 127-149 \\
\hline
\end{tabular}


ideológico para a reprodução da própria sociabilidade capitalista, respondendo assim as funções que se estabelecem entre a educação formal, o Estado e a manutenção da própria luta de classes.

Sobre a cidadania e sua relação com a forma política estatal, argumenta Alysson Leandro Mascaro (2013):

A forma política estatal e a forma jurídica, derivadas necessárias da forma mercadoria, constituem os indivíduos, no capitalismo, não como membros de determinadas classes ou grupo, mas sim como sujeitos de direitos e cidadãos. É por meio de tais formas e suas ferramentas correlatas - direitos subjetivos e deveres, voto - que a pressão social é retrabalhada pelo Estado. Assim, a forma política estatal e a forma jurídica, envolvidas num complexo funcional, representam num nível formal ótimo à própria reprodução da mercadoria e, por extensão, ao próprio capital. De modo geral, as lutas das classes não avançam como tais nas teias dos Estados, ficando retidas nas categorias da forma política - cidadão, voto e representação - e da forma jurídica - cumprimento de direitos subjetivos e deveres dos sujeitos de direito, pessoa física e pessoa jurídica (MASCARO, 2013, p. 49-50)

E, por fim, o que se pode dizer é que essa separação entre "educação" e "prática social" não consegue compreender que existe uma "educação contínua" da ordem estabelecida que se dá em todos os tempos da vida cotidiana no mundo moderno (dentro e fora da universidade, da escola, do trabalho, da casa e, sobretudo, na rua) e que tem, exatamente, como núcleo da consciência dominante a "imposição arbitrária da crença na absoluta inalterabilidade de suas determinações estruturais fundamentais" que compõe as formas sociais de acumulação de capital e, entre elas, a aceitação dos poderes que colocam a grande massa de humanos na condições de explorados (MÉSZÁROS, 2008, p. 82$)^{14}$

\footnotetext{
${ }^{14}$ Argumenta István Mészáros (2008, p. 81-82): "Nesse sentido, podemos ver que, embora o período de educação institucionalizada seja limitado sob o capitalismo a relativamente poucos anos da vida dos indivíduos, a dominação ideológica da sociedade prevalece por toda a sua vida, ainda que em muitos contextos essa dominação não tenha de assumir preferências doutrinárias explícitas de valor. E isso torna mais pernicioso o problema do domínio ideológico do capital sobre a sociedade como um todo e, por certo, ao mesmo tempo sobre seus indivíduos convenientemente isolados. Quer os indivíduos particulares tenha ou não consciência disso, não podem sequer encontra a mínima gota de fundamento disso, não podem sequer encontrar a mínima gota de fundamento neutro de valor em sua sociedade, muito embora a explícita doutrinação ideológica lhes garanta de forma enganosa o oposto, pretendendo - e convidando os indivíduos a se identificarem "autonomamente" com essa pretensão - que eles sejam plenamente soberanos em sua escolha dos valores em geral, assim como se afirma que eles são consumidores soberanos das mercadorias produzidas capitalisticamente, adquiridas com base nas escolhas soberanas
}

\begin{tabular}{|l|l|l|l|l|}
\hline Rovista Dialectus & Ano 4 & n. 10 & Janeiro - Julho 2017 & p. 127-149 \\
\hline
\end{tabular}


Ao financiar uma educação com uma mínima parte do que é arrecadado pelos cofres públicos; ao decidir a educação como uma prática de tempo limitado que tem a pretensão de formar apenas cidadãos para a vida coletiva abstrata realizadora da formamercadoria, ao exigir do professor uma jornada de trabalho que o impossibilita "tempo livre" para pensar, descansar, se formar-inserir teórico-socialmente e preparar o material artístico para o próprio labor intelectual, não nos resta dúvida, que o encontro entre Estado, educação e professor, nesses moldes, tem como síntese a concepção da escola como instituição realizadoras de tarefas de "equalização" e de "correção" contextual dos problemas que "desequilibram" e promovem a "desarmonia" da sociedade. Não cabe para o Estado compreender a escola como o lugar para a construção do "pensamento novo por parte dos educadores da própria escola", as reformas do Ensino Médio atual, a defesa da Escola Sem Partido e todos os trâmites para desviar o financiamento extensivo da Educação com os rendimentos promovidos pelo pré-sal, evidencia que as prioridades não é a Educação nem a formação profunda de um estudantes e professor para transformar a vida. A escola pensada pelo Estado e grandes centros financeiros continua tendo o papel de formar uma força de trabalho, hoje quase sem ter possibilidades de inserções, e, sobretudo, de treinar em grande medida as consciências para uma adaptação com a consciência dominante no mundo.

\section{Considerações}

Recompor o conceito de educação, fazendo a crítica a essas circunstâncias nas quais ela está inserida, no interior do Estado e na totalidade que tem como núcleo a forma mercadoria, é, primeiro, não banalizar que estamos numa sociedade contemporânea que tem seu cerne de sociabilidade na divisão social de trabalho - do trabalho intelectual e do trabalho material - dividida no interior da luta de classes; segundo, cabe revelar que esses processos de trabalho e de exploração da força de trabalho foram e são construídos socialmente, logo são experiência espaço-temporais, não pertencendo a resolução dos problemas ao mundo da metafísica ou do direito, mas na luta concreta da vida social; terceiro, o caráter dessa concepção de educação assume uma crítica a contemplação do mundo e concebe que o papel da "palavra ensinada" e das "aprendizagens" não podem, nesse mundo, desvincular a questão da educação com

nos supermercados controlados de modo cada vez monopolista. Tudo isso é uma parte integrante da educação capitalista pela qual os indivíduos particulares são diariamente e por toda parte embebidos nos valores da sociedade das mercadorias, como algo lógico e natural".

\begin{tabular}{|c|c|c|c|c|}
\hline Rovista Dialectus & Ano 4 & n. 10 & Janeiro - Julho 2017 & p. $127-149$ \\
\hline
\end{tabular}


a questão do trabalho. Como nos ensina Emir Sader (2008): "diga-me onde está o trabalho em um tipo de sociedade e eu te direi onde está a educação" (SADER, 2008, p. 17).

O professor Dermeval Saviani (1984) tem nos ensinado que não separar a concepção de educação da sociedade, está em conceber que a própria educação, que ele denomina de "fenômeno educativo", se realiza de acordo com as múltiplas determinações históricas em que está envolvida no interior de uma sociedade particular, não possuindo assim o grau de autonomia e peso social que lhes era dada pela concepção anterior. A concepção de educação não separada da prática social tem compreendido que as instituições de educação tem promovido a produção da sociedade de classes, tem reforçado os ajustes culturais das pautas do modo de produção capitalista e, desse modo, tem sido um fenômeno político e cultural de disciplina, encarceramento e de instrumentalidade da razão.

Mais uma vez Dermeval Saviani (1984), não querendo se perder entre os erros das teorias não críticas (tradicional, escolanovista e tecnicista) e no pessimismo da construção de uma teoria crítica que não percebe saídas e que pode conceber apenas a impotência dos trabalhadores frentes as instituições oficiais de educação do Estado, traz algumas afirmações e perguntas que achamos interessante expor para essa altura do texto:

Considerando-se que a classe dominante não tem interesse na transformação histórica da escola (ela está empenhada na preservação de seu domínio, portanto, apenas acionará mecanismos de adaptação que evitem a transformação) segue que uma teoria crítica só poderá ser formulado do ponto de vista dos interesses dos dominados. O nosso problema, então, pode ser enunciado da seguinte maneira: é possível articular a escola com os interesses dos dominados? É possível uma teoria da educação que capte criticamente a escola como um instrumento capaz de contribuir para a superação do problema da marginalidade? (...) Uma teoria do tipo acima enunciado se impõe a tarefa de superar tanto o poder ilusório como a impotência colocando na mão dos educadores uma arma de luta capaz de permitir-lhes o exercício de um poder real, ainda que limitado (...) Do ponto de vista prático, trata-se de retomar vigorosamente a luta contra a seletividade, a discriminação e o rebaixamento do ensino das camadas populares. Lutar contra a marginalidade através da escola significa engajar-se no esforço para garantir aos trabalhadores um ensino de melhor qualidade [crítica] possível nas condições históricas atuais. O papel de uma teoria crítica da educação é dar substância concreta a essa

\begin{tabular}{|l|l|l|l|l|}
\hline Qevista Dialectus & Ano 4 & n. 10 & Janeiro - Julho 2017 & p. 127-149 \\
\hline
\end{tabular}


bandeira de luta de modo a evitar que ela seja apropriada e articulada com os interesses dominantes (SAVIANI, 1984, p. 35-36).

Podemos afirmar que no Brasil contemporâneo os cursos superiores de Licenciatura em Educação do Campo (LEDOC), que tem a frente os movimentos sociais (o movimentos dos trabalhadores sem terra - o MST, Comissão Pastoral da Terra - CPT, Movimentos Quilombolas, por exemplo), tem promovido uma proposta dessa nova escola que se pode elaborar, tendo como pauta a luta contra o latifúndio e todos os meios de produção privatizados, assim, "contra o latifúndio do saber", bem como, "contra a colonialidade do saber que ainda é ensinado". Mesmo articulado, muitas vezes, com o Estado, os cursos de Licenciatura em Educação do Campo tem uma proposta de currículo e de pedagogia (pedagogia da alternância) que reorganiza a relação entre educação e realidade vivida, formação do professor e a universidade, sendo o projeto de leitura e transformação da sociedade capitalista algo inerente a diversidade de conteúdos estudados, isso independente das enormes dificuldades para abrir e sustentar novos cursos de formadores de educadores para o campo.

A concepção de educação como uma prática pensada no interior das múltiplas determinações da realidade dividida entre classes sociais, se apresenta, nessa esteira, como um campo de lutas. Primeiro, contra a exploração do trabalho assalariado em todas as suas instâncias; segundo, contra a ideologia da cidadania que enxerga o indivíduo como um "sujeito de direito"; terceiro, abre um enfrentamento direto com a concepção de educação vinculada a formação de mão de obra para o mercado de trabalho, rebatendo tal concepção como uma crítica as fantasmagorias que se ocultam na forma mercadoria; por último, a educação como campo de lutas nos possibilita erigir uma consciência de classe com todos aqueles que estão se preparando, contraditoriamente, para vender seus pedaços de tempo de vida, se formulando como um combate aberto e largo às formas de internalização das formas de conceber vinculadas ao mundo da mercadoria.

Fica claro na leitura de Mészáros (2008) que a concepção da educação não separada da prática social entende que acontece de maneira contínua "determinações educacionais gerais da sociedade", isto é, que ao nascer e viver na sociabilidade capitalista já nos é apresentado uma ideologia dominante que está sob o domínio do capital que tem como recado individual central que "cada indivíduo adote como suas

\begin{tabular}{|l|l|l|l|l|}
\hline Q Ronista Dialectus & Ano 4 & n. 10 & Janeiro - Julho 2017 & p. 127-149 \\
\hline
\end{tabular}


próprias as metas de reprodução objetivamente possíveis do sistema" (p.44), ou seja, nos alerta o autor que a externalidade da vida institucional da educação nos promove um ponto de partida para pensar o que seja a educação nesse sentido amplo, que está em todos os momentos do dia, dos meses e dos anos e, para o nosso caso aqui particular, pode nos servir de pressuposto para a formação do professor que pensa para além do capitalismo.

Argumenta Mészáros (2008):

No sentido verdadeiramente amplo do termo educação, trata-se de uma questão de "internalização" pelos indivíduos da legitimidade da posição que lhes foi atribuída na hierarquia social, juntamente com suas expectativas "adequadas" e as formas de conduta "certas", mais ou menos explicitamente estipuladas nesse terreno (...) As instituições formais de educação certamente são uma parte importante do sistema global de internalização. Mas apenas uma parte. Quer os indivíduos participem ou não - por mais ou menos tempo, mas sempre em um número de anos bastante limitado - das instituições formais de educação, eles devem ser induzidos a uma aceitação ativa (ou mais ou menos resignada) dos princípios reprodutivos orientadores dominantes na própria sociedade, adequados a sua posição na ordem social , e de acordo com as tarefas que lhe foram atribuídas (...) ao internalizar as onipresentes pressões externas, eles devem adotar as perspectivas globais da sociedade mercantilizada como inquestionáveis limites individuais a suas aspirações pessoais. Apenas a mais consciente das ações coletivas poderá livrá-los dessa grave e paralisante situação. Nessa perspectiva, fica bastante claro que a educação formal não é a força ideologicamente primária que consolida o sistema do capital; tampouco ela é capaz de, por si só, fornecer uma alternativa emancipadora radical. Uma das funções principais da educação formal nas nossas sociedades é produzir tanto a conformidade ou "consenso" quanto for capaz, a partir de dentro e por meio dos seus próprios limites institucionalizados e legalmente sancionados. Esperar da sociedade mercantilizada uma ação ativa - ou mesmo mera tolerância - de um mandato que estimule as instituições de educação formal a abraçar plenamente a grade tarefa da história do nosso tempo, ou seja, a tarefa de romper com a lógica do capital no interesse da soberania humana, seria um milagre monumental. É por isso que, também no âmbito educacional, as soluções não podem ser formais, elas devem sem essenciais. Em outras palavras, eles devem abarcar a totalidade das práticas educacionais da sociedade estabelecida. As soluções educacionais formais, mesmo algumas das maiores, e mesmo quando são sacramentada pela lei, podem ser completamente invertidas,

\begin{tabular}{|l|l|l|l|l|}
\hline Q Rovista Dialectus & Ano 4 & n. 10 & Janeiro - Julho 2017 & p. 127-149 \\
\hline
\end{tabular}


desde que a lógica do capital permaneça intacta como quadro de referências orientador da sociedade. (...) O que precisa ser confrontado e alterado fundamentalmente é todo o sistema de internalização, com todas as suas dimensões, visíveis e ocultas. Romper com a lógica do capital na área da educação, equivale, portanto, a substituir as formas onipresentes e profundamente enraizadas de internalização mistificadora por uma alternativa concreta abrangente (MÉSZÁROS, 2008, p. 45-47).

Esse sentido amplo de educação abre a possibilidade para problematizarmos que a aprendizagem é tudo aquilo que internalizamos no processo de reprodução das contradições da sociabilidade capitalista no tempo vivo, "que não passamos dez horas sem nada aprender” e, se assim é, torna-se necessário pensar que as instituições da educação formal podem nos ajudar a "tornar consciente esse processo de aprendizagem", "pode nos ajudar a perseguir o objetivo de uma mudança verdadeiramente radical, proporcionando instrumentos de pressão que rompam a lógica mistificadora do capital". As questões finais estão em romper, material e simbolicamente, a divisão entre o Homo faber do Homo sapiens (MÉSZÁROS, 2008, p. $48)^{15}$.

A formação do professor pensado nessa perspectiva da educação, primeiro, que não separa a educação da sociedade; segundo, que concebe as próprias determinações históricas como prenhes de processos educativos; abre para as possibilidades de que as experiências do mundo que todos tem nas particularidades que fazem parte, mais do que experiências, carregam as possibilidades para se atuar em coletivo (numa contra internalização mistificadora do indivíduo pertencente a uma comunidade nacional) que não podem ser modificados ao bel prazer de uma política pública, ou mesmo, de um mandato estatal. A constituição dessa concepção de contraconsciência ou anticapitalista nos provoca a entender que os projetos educativos ganham sentidos de continuidade e de reflexão com a própria vida e, no capitalismo, no mundo da exploração do trabalho. Não se trata de uso das experiências no sentido subjetivistas ou apenas no plano da psicologia existencialista, mas da ideia de que o sujeito constrói contraditoriamente sua

${ }^{15}$ Traz nessas circunstâncias uma clássica citação de Antonio Gramsci (1957): “... não há nenhuma atividade humana da qual se possa excluir qualquer intervenção intelectual - o Homo faber não poder ser separado do Homo sapiens. Além disso, fora do trabalho, todo homem desenvolve alguma atividade intelectual; ele é, em outras palavras, um filósofo, um artista, um homem com sensibilidade, ele partilha uma concepção de mundo, tem uma linha consciente de conduta moral, e portanto contribui para manter ou mudar a concepção de mundo, isto é, para estimular novas formas de pensamento" (GRAMSCI, 1957, p. 121). Ver GRAMSCI, Antonio. The Formation of Intellectuals. The Modern Prince and Other Writings. Londres: Lawrence and Wishart, 1957.

\begin{tabular}{|l|l|l|l|l|}
\hline Q Ronista Dialectus & Ano 4 & n. 10 & Janeiro - Julho 2017 & p. 127-149 \\
\hline
\end{tabular}


consciência como um ser social que faz parte de uma classe escravizada que negocia sua criatividade.

E, em tom de síntese, arremata Mészáros (2008):

Os princípios educadores da educação formal devem ser desatados do seu tegumento da lógica do capital, de imposição de conformidade, e em vez disso, mover-se em direção a um intercâmbio ativo e efetivo com práticas educacionais mais abrangentes. Eles (os princípios) precisam muito um do outro. Sem um progressivo e consciente intercâmbio com processo de educação abrangentes como "a nossa própria vida", a educação formal não pode realizar as suas muito necessárias aspirações emancipadoras. Se, entretanto, os elementos progressistas da educação formal forem bem-sucedidos em redefinir a sua tarefa num espírito orientado em direção a perspectiva de uma alternativa hegemônica a ordem existente, eles poderão dar uma contribuição vital para romper a lógica do capital, não só no seu propósito e mais limitado domínio como também na sociedade como um todo" (MÉSZAROS, 2008, p. 59)

Essa questão do papel do professor é central, principalmente, no momento histórico contemporâneo que tem criado bastante sinônimos (como, monitor, orientador, tutor, auxiliar, etc) que, no fundo, reflete uma mesma prática de fechamento e desarticulação das instituições com o mundo do trabalho e da formação de um estudante para essa vida de desapossamentos.

Se já sabemos que o Estado e todos aqueles que tem o monopólio do capital não vão financiar uma educação pública para além do capital, cabe colocar em nossa pauta que além de educar um educador para ensinar e fazer boas aulas didaticamente, temos que construir um ser político que se engaje nos movimentos sociais à favor de uma escola e uma educação libertadora e que tenha o tempo livre ou ocupado para ajudar na tarefa de construir uma sociedade que tenha no desenvolvimento máximo da criatividade humana e no reconhecimento de todos com os produtos dos trabalhos coletivos como perspectiva de superação da luta de classes. Não há outra via que não seja a formação de um professor para enfrentar tudo isso pela travessia das manifestações, da revolução permanente, da busca destruição do Estado, da construção da autogestão e da organização política via assembleias gerais, dos conselhos e das federações, enfim, da liberdade humana.

Os cursos de Licenciatura em Educação do Campo, em certas proporções, acolhem os principais pontos da concepção marxista de Educação e o conjunto das

\begin{tabular}{|l|l|l|l|l|}
\hline Q Rovista Qialoctus & Ano 4 & n. 10 & Janeiro - Julho 2017 & p. 127-149 \\
\hline
\end{tabular}


preocupações dos trabalhadores na luta por educação: a) mesmo que entendam que as instituições de educação formal façam parte da dinâmica da sociedade produtoras de mercadoria, sabem que a luta pela educação é uma forma de acesso ao saber acumulado historicamente; b) além do saber formal acumulado, os movimentos sociais do campo lutam para elaborar um currículo com os conteúdos que fortaleçam as experiências dos camponeses e das camponesas no campo, associado a práxis política, a identidade como camponês e a resistência a expropriação; c) como espaço de socialização do conhecimento, a Educação do Campo articula atividades de trabalho e os conhecimentos estudados, produzindo um currículo alternado entre atividade material e atividade intelectual, reunindo a separação entre os que pensam e os que fazem; d) por fim, mesmo pública e financiada pelo Estado, os cursos de Educação do Campo tem conseguido dirigir suas reivindicações e exigências para o Estado sem perder uma certa autonomia política das proposições educativas, tornando esse projeto um aspecto da contradição que a educação formal pode assumir perante a sociedade produtora de mercadoria $^{16}$.

É nessa travessia que a partir de Bernardo Mançano Fernandes temos entendido que "a Educação do Campo vem sendo construída pelos movimentos camponeses a partir do princípio da autonomia dos territórios materiais [campo com espaço de vida] e imaterais [Educação]" (FERNANDES, 2006, p. 9). E, sobretudo, como uma forma de apontar a educação para a reprodução da vida do campesinato e para a formação de uma consciência que luta pela transformação radical no campo, isso quando se tem como base de entendimento no currículo as contradições postas no contexto da questão agrária num país marcado pela concentração da estrutura fundiária, a grilagem de terras, o trabalho análogo a escravidão e a exploração da força de trabalho de crianças e adultos camponeses.

A partir do estudo da dinâmica tensa e complexa, do contexto social do campo, das tensões econômicas, sociais, políticas, culturais, que marcam a escola e, sobretudo, seus sujeitos mestres, alunos, famílias, comunidades. Conhecer essas realidades, formar nas capacidades, artes, e sensibilidades sociais para conhecê-las, pesquisá-las, teorizá-las. Para nelas

\footnotetext{
${ }^{16}$ Sobre os pontos centrais da concepção de Educação para Marx, que guiam aqui nossa compreensão sobre a Educação do Campo, ver: SOUSA JUNIOR, Justino de. A Crítica Marxiana da Educação em Tempos de Mundialização do Capital e Crise da Escola. Revista Trabalho Necessário. Ano 2, no 2, 2004, p. 1-24.
}

\begin{tabular}{|c|c|c|c|c|}
\hline Rovista Alalectus & Ano 4 & n. 10 & Janeiro - Julho 2017 & p. $127-149$ \\
\hline
\end{tabular}


intervir passa a ser central nos perfis de docente-educador a ser formado (ARROYO, 2010, p. 13-14).

Defendemos a formação do professor entendido também como pesquisador não isolado da vida criativa e intelectual transformadora da realidade social. Acreditamos que a educação de/para resistência tem que revelar as possibilidades de rupturas com as estruturas tradicionais de educação (que toma como propósito maior a reprodução do conhecimento científico em subterfúgios de saberes setorizados). Busca-se, por meio dessa concepção a saída do autoritarismo do "praticismo" educativo, através da afirmação social da ciência, das experiências dialéticas no/do ensino para além das salas de aula e definição política do professor (FREIRE, 1985) contextualizado com as experiências política radical de enfrentamento a padrões de consciências e ajuste profissional conjugados a reprodução da mais-valia e flexibilização do trabalho docente na educação formal neoliberal.

\section{Referências}

ARROYO, Miguel. Educação do Campo: movimentos sociais e formação docente. Revista Marco Social - Educação do Campo. Instituto Souza Cruz, 2010, p. 12-15.

ADORNO, Theodor. Mensagens numa Garrafa.Tradução de Vera Ribeiro. Rio de Janeiro: Contraponto, 1996 (p. 39-50).

ANDERSON, Perry. Linhagens do Estado Absolutista. São Paulo: Brasiliense, 2004.

ANDRADE, Carlos Drummond de. Hino Nacional. In:. Carlos Drummond de Andrade. Vol. 01. Rio de Janeiro: BestBolso, 2010.

DAMIANI, Amélia Luisa. A geografia e a construção da cidadania. In. Carlos, Ana Fani Alessandri. A Geografia na Sala de Aula. São Paulo: Contexto, 2006 (p. 50-61).

DUARTE, Newton. Sociedade do conhecimento ou sociedade das ilusões? quatro ensaios crítico-dialéticos em filosofia da educação. Campinas, SP: Autores Associados, 2008.

FERNANDES, B. M. Os campos da pesquisa em educação do campo: espaço e território como categorias essenciais. A pesquisa em Educação do Campo, v. XX, p. X-I, 2006.

FREIRE, Paulo. Pedagogia da Autonomia: saberes necessários à prática educativa. São Paulo: Paz e Terra, 1996.

FREIRE, Paulo. Pedagogia do Oprimido. Rio de Janeiro: Paz e Terra, 1985.

\begin{tabular}{|l|l|l|l|l|}
\hline Govista Qialectus & Ano 4 & n. 10 & Janeiro - Julho 2017 & p. 127-149 \\
\hline
\end{tabular}


GENTILI, Pablo A.A. A falsificação do consenso: simulacro e imposição na reforma educacional do neoliberalismo. Petrópolis, RJ: Vozes, 1998. P.13-39.

HARVEY, David. Condição pós-moderna. São Paulo: Edições Loyola, 1992.

Espaços de Esperanças. São Paulo: Edições Loyola, 2004.

Para Entender 'O Capital' (Livro I). São Paulo: Boitempo, 2013.

HOBSBAWM, Eric. A Era do Capital. São Paulo: Paz e Terra, 2007.

KRAWCZYK, Nora;VIEIRA, Vera Lúcia. A reforma educacional na América Latina: uma perspectiva histórico-sociológica. São Paulo: Xamã, 2008.pp.47-73.

MARX, Karl. Crítica da Filosofia do Direito de Hegel. São Paulo: Boitempo, 2005.

O Capital: crítica da economia política. 24ed. Rio de Janeiro: Civilização Brasileira, 2006.

O 18 de Brumário de Luís Bonaparte. São Paulo: Boitempo, 2011.

MASCARO, Alysson L. A Crítica do Estado e do Direito: a forma política e a forma jurídica. Anais do IV Curso Livre Marx e Engels: A Criação Destruidora. São Paulo: Boitempo, 2013a (p.14-18)

Estado e Forma Política. São Paulo: Boitempo, 2013b

MÉSZÁROS, Istvan. Para Além do Capitalismo. São Paulo: Boitempo, 2008

SADER, Sader. Prefácio. In. Para Além do Capitalismo. São Paulo: Boitempo, 2008.

SANTOS, Milton. O Espaço do Cidadão. São Paulo: Edusp, 2012.

SAVIANI, Dermeval. História das ideias pedagógicas no Brasil. 2. Ed. Campinas, SP: Autores Associados, 2008.

SOUSA JUNIOR, Justino de. A Crítica Marxiana da Educação em Tempos de Mundialização do Capital e Crise da Escola. Revista Trabalho Necessário. Ano 2, $\mathrm{n}^{\mathrm{o}}$ 2, 2004, p. 1-24.

PERONI, Vera. Política Educacional e Papel do Estado. São Paulo: Xamã, 2003.pp.74-109.

\begin{tabular}{|c|c|c|c|c|}
\hline Rovista Dialectus & Ano 4 & n. 10 & Janeiro - Julho 2017 & p. $127-149$ \\
\hline
\end{tabular}

